Jurnal Satyagraha

Vol. 03, No. 02, Agustus 2020 - Januari 2021

ISSN : 2620-6358

http://ejournal.universitasmahendradatta.ac.id/index.php/satyagraha

\title{
PENGARUH KUALITAS LAYANAN DAN KUALITAS PRODUK TERHADAP KEPUASAN NASABAH TABUNGAN PADA KANTOR BANK BRI CABANG DENPASAR RENON
}

\author{
Oleh : \\ I Putu Ardinada, Ni Ketut Murdani dan Ni Luh Ketut Ayu Sudha Sucandrawati \\ Fakultas Ekonomi Universitas Mahendradatta
}

\begin{abstract}
ABSTRAK
Penelitian ini dilakukan berdasarkan kesenjangan hasil penelitianterdahulu (research gap) dan perbedaan fokus bahasan tentang Kualitas Layanan dan Kualitas Produk Terhadap Kepuasan Nasabah Tabungan Pada PT. BRI Cabang Denpasar Renon.Selain itu, terdapat pulapermasalahan penelitian (research problem) tentang tidak tercapainya target pada PT. BRI Cabang Denpasar Renon.

Penelitian inibertujuan untuk menguji dan menganalisis pengaruh kualitas layanan dan kualitas produk terhadap kepuasan nasabah tabungan pada PT. BRI Cabang Denpasar Renon. Penelitian ini dilakukan pada PT. BRI Cabang Denpasar Renon dengan populasi berjumlah 14.250 dan sampelpenelitian ini berjumlah 100 responden dihitung menggunakan rumus slovin.Seluruh data yang diperoleh dari distribusi kuisoner layak digunakan, selanjutnyadianalisis menggunakan SPSS 24.0.

Hasil penelitian menunjukkan bahwa (1) kualitas layanan berpengaruhpositif dan signifikan terhadap kepuasan nasabah, (2) kualitas produk berpengaruh positif dan signifikan terhadap kepuasan nasabah, dan (3) kualitaslayanan dan kualitas produk berpengaruh terhadap kepuasan nasabah.Implikasi dari penelitian ini bahwa kualitas pelayanan dapat ditingkatkandengan memperhatikan indikator berwujud, keandalan, ketanggapan, jaminan dankepastian dan empati agar semakin meningkat. Kepuasannasabah dapat ditingkatkan dengan memperhatikan indikator terpenuhinyaharapan nasabah, perasaan puas menggunakan produk, kepuasan terhadapfasilitas, kepuasan dengan nasabah dan kepuasan secara menyeluruh agar kepuasan nasabah dapatditingkatkan dengan memperhatikan indikator tujuan dalam membeli sebuahproduk, pemrosesan informasi untuk sampai ke pemilihan merk, memberikanrekomendasi kepada orang lain dan melakukan pembelian ulang.

Kata kunci: kualitas layanan, kualitas produk dan kepuasan nasabah.
\end{abstract}

I Putu Ardinada

Ni Ketut Murdani

Ni Luh Ketut Ayu Sudha Sucandrawati 
Jurnal Satyagraha

Vol. 03, No. 02, Agustus 2020 - Januari 2021

ISSN : 2620-6358

http://ejournal.universitasmahendradatta.ac.id/index.php/satyagraha

\begin{abstract}
This research was conducted based on the gap in research resultsPreviously (research gap) and the different focus of discussion on Service Quality and ProductQuality on Savings Customer Satisfaction at PT. BRI Denpasar Branch Renon. In addition, there are also research problems about not achieving targets at PT. BRI Denpasar Branch Renon.

This study aims to examine and analyze the effect of service quality and product quality on satisfaction of savings customers at PT. BRI Denpasar Branch Renon. This research was conducted at PT. BRI Denpasar Branch Renon with a population of 14,250 and the sample of this study amounted to 100 respondents calculated using the Slovin formula All data obtained from the questionnaire distribution are worthy of use, thenanalyzed using SPSS 24.0.

The results showed that (1) service quality has a positive and significant effect on customer satisfaction, (2) product quality has a positive and significant effect on customer satisfaction, and (3) service quality and product quality have an effect on customer satisfaction.The implication of this study is that the quality of service can be improvedby observing tangible indicators, reliability, responsiveness, guarantees andcertainty and empathy to increase.
\end{abstract}

Keywords: service quality, product quality and customer satisfaction.

\section{PENDAHULUAN}

Penelitian ini dilakukan berdasarkan kesenjangan hasil penelitian terdahulu (research gap) dan perbedaan fokus bahasan tentang Kualitas Layanan dan Kualitas Produk terhadap Kepuasan Nasabah Tabungan Pada PT. BRI Cabang Denpasar Renon.

Kepuasan nasabah merupakan orientasi pemasaran yang semakin penting untuk dilaksanakan dalam pengembangan tujuan PT.Bank BRI Cabang Denpasar Renon, sehingga kepuasan nasabah dapat digunakan sebagai sarana promosi penting bagi perusahaan. Disisi lain kepuasan nasabah juga berfungsi sebagai promosi murah perusahaan karena nasabah mau merekomendasi kepada calon nasabah baru untuk memanfaatkan fasilitas PT. Bank BRI Cabang Denpasar Renon.Dalam rangka meningkatkan kepuasan nasabah, PT. Bank BRI Cabang Denpasar Renon meningkatkan kualitas layanannyadan kualitas produk untuk merangsang terjadinya memenuhi kepuasan nasabah sehingga berdampak pada keinginan nasabah untuk menceritakan pengalamannya setelah menikmati fasilitas PT.Bank BRI Cabang Denpasar Renon.

Penelitian ini bertujuan untuk menguji dan menganalisis pengaruh kualitas layanan

I Putu Ardinada

Ni Ketut Murdani

Ni Luh Ketut Ayu Sudha Sucandrawati 
Jurnal Satyagraha

Vol. 03, No. 02, Agustus 2020 - Januari 2021

ISSN : 2620-6358

http://ejournal.universitasmahendradatta.ac.id/index.php/satyagraha

dan kualitas produk terhadap kepuasan nasabah tabungan pada PT. BRI Cabang Denpasar Renon. Penelitian ini dilakukan pada PT. BRI Cabang Denpasar Renon dengan populasi berjumlah 14.250 dan sampelpenelitian ini berjumlah 100 responden dihitung menggunakan rumus slovin.Seluruh data yang diperoleh dari distribusi kuisoner layak digunakan, selanjutnyadianalisis menggunakan SPSS 24.0.

\section{Pengertian Kualitas Layanan}

Kualitas layanan sering dikondisikan sebagai perbandingan antara pelayanan yang diharapakan dan pelayanan yang diterima secara nyata oleh nasabah Parasuraman et al.(2013). Pelayanan yang baik merupakan syarat utama kesuksesan bagi perusahaan jasa. Perusahaan yang mampu menawarkan kualitas pelayanan yang berkelanjuatan akan mempunyai keunggulan kompetitif dalam bisnis apapun, hal ini memungkinkan perusahaan untuk memenuhi tidak hanya kebutuhan nasabah saat ini tetapi juga untuk mengantisipasi kebutuhan masa depan nasabah Mubbsher et al., (2014).

Hamad Saleem et al. (2014) menyatakan kualitas pelayanan merupakan pertimbangan yang sangat penting, sehingga perusahaan berusaha mencapai kepuasan nasabah secara maksimal dengan menyediakan pelayanan yang berkualitas.Persaingan yang semakin ketat akhi-akhir ini menuntut sebuah lembaga penyedia jasa/layanan untuk selalu memanjakan konsumen/pelanggan dengan memberikan pelayanan terbaik. Para pelanggan akan mencari produk barang atau jasa dari perusahaan yang dapat memberikan pelayanan terbaik kepadanya Assauri, (2013). Kualitas pelayanan merupakan komponen penting dalam persepsi konsumen, juga sangat penting dalam pengaruhnya terhadap kepuasan nasabah. Semakin baik kualitas jasa yang diberikan maka akan semakin baik pula citra jasa tersebut dimata konsumen.Menurut Zeithamlet al. (2016) ciri-ciri dari kualitas jasa adalahsebagai berikut : 1) Kualitas jasa sangat sulit untuk dilakukan evaluasi dibandingkan dengan kualitas barang; 2) Kualitas jasa merupakan perbandingan hasil dari pandangan konsumen antara harapan dan kenyataan; 3) Kriteria untuk menentukan kualitas jasa akhirnya dikembalikan kepada konsumen sendiri. Pandangan pada suatu kualitas jasa dimulai bagaimana penyedia jasa dapat memenuhi harapan konsumen.

\section{Pengertian kualitas produk}

Kualitas produk merupakan fokus utama dalam perusahaan, kualitas merupakan salah satu kebijakan penting dalam meningkatkan daya saing produk yang utama memberi kepuasan kepada konsumen yang melebihi atau paling tidak sama dengan kualitas produk dari pesaing.Kualitas mencakup produk, jasa, manusia, proses dan lingkungan. Pada sisi yang lain kualitas juga merupakan kondisi yang selalu berubah (misalnya apa yang dianggap merupakan kualitas saat ini mungkin dianggap kurang berkualitas pada masa yang akan datang).Pengertian atau definisi kualitas dapat berbeda makna bagi setiap orang, karena kualitas memiliki banyak kriteria dan sangat tergantung pada konteksnya. Banyak pakar dibidang kualitas yang mencoba untuk

I Putu Ardinada

Ni Ketut Murdani

Ni Luh Ketut Ayu Sudha Sucandrawati 
Jurnal Satyagraha

Vol. 03, No. 02, Agustus 2020 - Januari 2021

ISSN : 2620-6358

http://ejournal.universitasmahendradatta.ac.id/index.php/satyagraha

mendefinisikan kualitas berdasarkan sudut pandang masing-masingYamit, (2013:7).

Menurut Kotler dan Armstrong (2013:272) kualitas produk adalah salah satu sarana positioning utama pasar. Kualitas mempunyai dampak langsung pada kinerja produk atau jasa. Oleh karena itu, kualitas berhubungan erat dengan nilai dan kepuasan pelanggan.

Titin (2016) Kualitas produk merupakan salah satu alat pemasaran yang penting dalam menempatkan posisi suatu produk di pasar. Kualitas adalah kemampuan suatu produk untuk memenuhi fungsi-fungsinya Simamora, (2015:147).

Wahjono (2013:88) produk adalah kesetiaan nasabah pada produk yang ditawarkan dipasar untuk mendapatkan perhatian, permintaan, pemakaian atau konsumsi yang dapat memenuhi keinginan atau kebutuhan manusia.

Machfoedz (2015:125) kualitas produk adalah kemampuan produk untuk menjalankan fungsinya meliputi keawetan, keandalan, kemudahan penggunaan dan perbaikannya, serta sifat lainnya. Sehingga perusahaan yang kualitas produknya berkualitas baik yang akan tumbuh pesat dalam jangka panjang dibandingkan perusahaan lainnya.

Berdasarkan definisi-definisi tersebut, maka dapat disimpulkan bahwa kualitas merupakan usaha yang dilakukan oleh perusahaan untuk memenuhi atau bahkan melebihi atau melibihi harapan pelanggan dan pada dasarnya kualitas produk menggambarkan sejauh mana kemampuan suatu produk untuk menampilkan kemampuannya atau melaksanakan fungsi-fungsi yang dimilikinya.

\section{Pengertian kepuasan nasabah}

Kunci keberhasilan suatu usaha terletak pada kepuasan nasabah.Hal ini dikarenakan dengan memuaskan nasabah, organisasi dapat meningkatkan tingkat keuntungannya dan mendapatkan pangsa pasar yang lebih luas.Karena kepuasan merupakan faktor penting maka banyak studi dilakukan untuk mengukur kepuasan nasabah, sehingga banyak definisi dari kepuasan nasabah.

Kepuasan Nasabah dapat didefinisikan sebagai evaluasi kesadaran dan kecintaan Konsumen terhadap barang atau jasa yang telah disampai kepadanya oleh produsen tertentu Birgelen et al,(2013). Kepuasan dipengaruhi oleh tingkat harapan atas kualitas jasa (Cronin dan Taylor. 2013).Kepuasan nasabah sebagai hasil dari perbandingan antara harapan produk atau jasa dan kenyataan yang diterima seseorang maka memunculkan dua kemungkinan yang pertama adalah bila penjual memberikan informasi yang berlebihan terhadap nasabah, maka nasabahakan mempunyai pengharapan yang terlalu tinggi, sehingga berakibat ketidakpuasan jika penjual tidak dapat memenuhi informasinya. Kemungkinan kedua adalah bila penjual tidak dapat memenuhi informasi kepada nasabah, maka nasabahakan kurang tertarik (harapannya rendah) pada produk atau pelayanan tersebut, sehingga transaksi tidak akan terjadi.

Rangkuti (2016:30) kepuasan nasabah didefinisikan sebagai respon konsumen terhadap ketidaksesuaian antara tingkat kepentingan sebelumnya dan kinerja aktual yang dirasakannya setelah pemakaian.Kotler

I Putu Ardinada

Ni Ketut Murdani

Ni Luh Ketut Ayu Sudha Sucandrawati 
Jurnal Satyagraha

Vol. 03, No. 02, Agustus 2020 - Januari 2021

ISSN : 2620-6358

http://ejournal.universitasmahendradatta.ac.id/index.php/satyagraha

dalam Hamdani, (2016:191) kepuasan Konsumen merupakan tingkat perasaan dimana seseorang menyatakan hasil perbandingan atas kinerja produk yang diterima dan yang diharapkan.Kepuasan pelanggan adalah perasaan internal setiap individu yang mungkin kepuasan atau ketidakpuasan yang diakibatkan oleh penilaian layanan yang diberikan kepada individu sesuai dengan keinginan pelanggan antisipasi oleh sebuah organisasi Oliver, (2014).

Engel et al. dalam Tjiptono, (2013:146) mengungkapkan bahwa kepuasan konsumen merupakan evaluasi purna beli dimana alternatif yang dipilih sekurang-kurangnya memberikan hasil (outcome) sama atau melampaui harapan konsumen, sedangkan ketidakpuasan timbul apabila hasil yang diperoleh tidak memenuhi harapan konsumen.

Dari definisi di atas, dapat disimpulkan bahwa kepuasan nasabah merupakan hasil perbandingan yang dirasakan antara kinerja produk dan kesesuaian harapan yang diinginkan nasabah setelah melakukan pembelian, Jika produk sesuai atau melampaui harapan nasabah maka nasabahakan merasa puas dan sebaliknya jika produk tidak sesuai dengan harapan, maka nasabahtidak merasa puas.

\section{METODE PENELITIAN}

Populasi dalam penelitian ini adalah seluruh nasabah aktif PT. Bank BRI Cabang Denpasar dan hanya berupa nasabah tabungan yang berada pada rentang usia 18 sampai 65 tahun keatas, yang berjumlah 14.250 nasabah tabungan.Adapun kriteria dari penentuan sampel terkait pendidikan yaitu minimal SMA atau sederajat dengan jumlah sampel sebanyak 100 orang.

Teknik yang digunakan dalam pengumpulan data adalah : wawancara, dokumentasi dan kuisioner, sedangkan teknik analisis data menggunakan pendekatan kuantitatif dengan analisis statistik yang diolah dengan paket program komputer SPSS. Analisis data tersebut meliputi analisis regreli linier berganda, analisis koefisien regresi, dab analisis determinasi.

\section{HASIL PENELITIAN}

Hasil pengujian hiopotesis analisis regresi linier berganda dengan menggunakan bantuan paket komputer SPSS menunjukan persamaan sebagai berikut :

$$
\mathrm{Y}=1.536+0.328 \mathrm{X}_{1}+0.287 \mathrm{X}_{2}
$$

Artinya bahwa kualitas layanan $\left(\mathrm{X}_{1}\right)$ dapat mempengaruhi kepuasan nasabah PT. Bank BRI Kantor Cabang Denpasar sebesar 0.328.Demikian pula kualitas produk $\left(\mathrm{X}_{2}\right)$ dapat meningkatkan kepuasan nasabah PT. Bank BRI Kantor Cabang Denpasar sebesar 0,287 .

Dengan analisis koefisien regredi $(\mathrm{r})$ diperoleh nilai sebesar 0,697, artinya bahwa kualitas layanan dan kualitas produk memiliki pengaruh yang positif dan signifikan terhadap kepuasan nasabah PT. Bank BRI Kantor Cabang Denpasar.

Dengan analisis koefisien determinasi diperoleh nilai sebesar 0,475 yang berarti bahwa tinggi rendahnya kepuasan nasabah PT. Bank BRI Kantor Cabang Denpasar dipengaruhi oleh kualitas layanan dan kualitas

I Putu Ardinada

Ni Ketut Murdani

Ni Luh Ketut Ayu Sudha Sucandrawati 
Jurnal Satyagraha

Vol. 03, No. 02, Agustus 2020 - Januari 2021

ISSN : 2620-6358

http://ejournal.universitasmahendradatta.ac.id/index.php/satyagraha

produk sebesar $47,50 \%$, sedangkan sisanya sebesar $43,50 \%$ dipengaruhi oleh faktor lain yang tidak disebutkan dalam penelitian ini.

\section{PEMBAHASAN}

Dari hasil penelitian yang diperoleh, maka dapat dilakukan pembahasan berdasarkan hasil tersebut, sebagai berikut :

Pengaruh kualitas layanan $\left(\mathrm{X}_{1}\right)$ terhadap kepuasan nasabah (Y) adalah signifikan, memiliki hubungan yang kuat dan bernilai positif (searah) dengan kepuasan nasabah.Hasil ini mengandung arti bahwa semakin baik kualitas layanan yang dimiliki PT. Bank BRI Cabang Denpasar Renon maka dapat meningkatkan kepuasan nasabah.Untuk itu hipotesis yang diajukan dalam penelitian ini "diterima".

Hasil ini sesuai dengan penelitian sebelumnya yang dilakukan Pradhana (2015) tentang analisis pengaruh kualitas produk dan kualitas layanan terhadap loyalitas pelanggan dengan kepuasan pelanggan sebagai intervening (Studi Kasus Pada Lumpia Mbak Lien Semarang) menggunakan sampel 150 pelanggan dan data diolah dengan (Structural Equation Modelling) SEM yang menggunakan bantuan program AMOS 22 for Windows. Penelitian ini menyatakan bahwa kualitas layanan memiliki pengaruh yang positif dan signifikan terhadap kepuasan pelanggan.

Penelitian Setyani (2014) tentang analisis pengaruh kualitas pelayanan dan kepercayaan terhadap loyalitas pelanggan melalui kepuasan pelanggan (Studi Pada Griya Kecantikan Aura Kota Semarang) yang menyatakan bahwa terdapat pengaruh yang positif dan signifikan antara kualitas layanan terhadap kepuasan nasabah.

Penelitian Naryawan (2013) tentang analisis pengaruh kualitas layanan terhadap kepuasan mahasiswa pengguna jasa perpustakaan referensi FE UNDIP menunjukkan bahwa variabel bukti fisik, keandalan, ketanggapan, jaminan dan empati berpengaruh positif terhadap kepuasan mahasiswa.Penelitian menggunakan data 100 responden dengan menggunakan metode accidental sampling dan menggunakan analisis linear berganda.

Penelitian Budiyanto (2013) dalam penelitiannya Pengaruh Kualitas Pelayanan Terhadap Loyalitas Pelanggan Dengan Kepuasan Pelanggan Sebagai Variabel Mediasi (Studi Pada UD.Adi Mbarep Sukoharjo) yang menggunakan sampel sejumlah 40 responden diambil dari pelanggan UD.Adi Mbarep dengan alat uji path analysis dengan Amos 4, menyatakan bahwa kualitas pelayanan berpengaruh positif dan signifikan pada kepuasan pelanggan.

Pelitian Fajarini (2016) tentang Pengaruh Kualitas Layanan Terhadap Kepercayaan Dan Loyalitas Nasabah Dimediasi Kepuasan Nasabah (Studi Kasus Klinik Kecantikan Beauty Inc Jakarta Barat) dengan sampel sebanyak 205 responden dengan menggunakan teknik purposive sampling.Metode analisis data yang digunakan adalah analisis faktor, alpha cronbach dan analisis Structural Equation Model (SEM).Penelitian ini menyatakan kualitas layanan berpengaruh positif dan signifikan terhadap kepuasan nasabah.

I Putu Ardinada

Ni Ketut Murdani

Ni Luh Ketut Ayu Sudha Sucandrawati 
Jurnal Satyagraha

Vol. 03, No. 02, Agustus 2020 - Januari 2021

ISSN : 2620-6358

http://ejournal.universitasmahendradatta.ac.id/index.php/satyagraha

Penelitian Shandy Widjoyo Putro, dkk (2014) dalam penelitiannya tentang Pengaruh Kualitas Layanan Dan Kualitas Produk Terhadap Kepuasan Nasabah Dan Loyalitas Nasabah Restoran Happy Garden Surabaya menyatakan kualitas produk berpengaruh positif dan signifikan terhadap kepuasan nasabah. Penelitian ini menggunakan 160 responden menggunakan metode purposive sampling dengan teknik analis yang dugunakan Structural Equation Modeling (SEM).

\section{PENUTUP}

Hasil penelitian menunjukkan bahwa (1) kualitas layanan berpengaruh positif dan signifikan terhadap kepuasan nasabah, (2) kualitas produk berpengaruh positif dan signifikan terhadap kepuasan nasabah, dan (3) kualitaslayanan dan kualitas produk berpengaruh terhadap kepuasan nasabah.

Implikasi dari penelitian ini bahwa kualitas pelayanan dapat ditingkatkan dengan memperhatikan indikator berwujud, keandalan, ketanggapan, jaminan dan kepastian serta empati agar semakin meningkat.

Kepuasan nasabah dapat ditingkatkan dengan memperhatikan indikator terpenuhinya harapan nasabah, perasaan puas menggunakan produk, kepuasan terhadap fasilitas, kepuasan dengan nasabah dan kepuasan secara menyeluruh agar kepuasan nasabah dapat ditingkatkan dengan memperhatikan indikator tujuan dalam membeli sebuahproduk, pemrosesan informasi untuk sampai ke pemilihan merk, memberikan rekomendasi kepada orang lain dan melakukan pembelian ulang.

\section{DAFTAR PUSTAKA}

Assauri, Sofjan. 2003. Customer Service yang Baik Landasan Pencapaian Customer Satisfaction dalam Usahawan, No. 01, Tahun XXXII, Januari, Jakarta.

Budiyanto. 2013. Pengaruh kualitas pelayanan terhadap loyalitas pelanggan dengan kepuasan pelanggan sebagai variabel mediasi (Studi Pada UD. Adi Mbarep Sukoharjo). Jurnal Manajemen. Vol 2 No 1.

Birgelen, Ruyter \& Wetzels. 2013. Emotional Satisfaction of Customer Contact. Universteit Van Amsterdam.

Cronin, J.J., Jr and S.A. Taylor, 2013.Measuring Service Quality: A Reexamination and Extension, Journal of Marketing, 56: 53-68.

Deny Irawan dan Edwin Japarianto. 2013. Analisa Pengaruh Kualitas Produk Terhadap Loyalitas Melalui Kepuasan Sebagai Variabel Intervening Pada Nasabah Restoran Por Kee Surabaya.Jurnal bisnis ekonomi.Vol 2 No 2.

Dharmayanti, Diah. 2016. Analisis Dampak Service Performance Dan Kepuasan Sebagai Moderating Variable Terhadap Loyalitas Nasabah (Studi pada Nasabah Tabungan Bank Mandiri Cabang Surabaya). Jurnal manajemen pemasaran, Vol. 1, No. 1, april 2006: 35-43.

I Putu Ardinada

Ni Ketut Murdani

Ni Luh Ketut Ayu Sudha Sucandrawati 
Jurnal Satyagraha

Vol. 03, No. 02, Agustus 2020 - Januari 2021

ISSN : 2620-6358

http://ejournal.universitasmahendradatta.ac.id/index.php/satyagraha

Fajarini 2016 Pengaruh Kualitas layanan Terhadap Kepercayaan Dan Loyalitas Nasabah Dimediasi Kepuasan Nasabah (Studi Kasus Klinik Kecantikan Beauty Inc Jakarta Barat) Vol. 1, No. 1.

Felix., J.F. 2017. Pengaruh citra toko dan kepuasan konsumen terhadap minat beli ulang PT. Urban Ritel Mandiri.Skripsi.

Freedy Rangkuti. 2016. Riset Pemasaran. Jakarta : Gramedia Pustaka Utama.

Ghozali, I., 2012. Structural Equation Modeling : Metode Alternatif Dengan Partial Least Square. Semarang : Badan Penerbit Universitas Diponegoro.

Hamdani, A. 2016.Manajemen Pemasaran Jasa. Edisi kedua.Jakarta : Salemba Empat.

Hamad Saleem, Naintara Sarfraz Raja. 2014. The Impact of Service Quality on Customer Satisfaction, Customer Loyalty and Brand Image: Evidence from Hotel Industry of Pakistan. IOSR Journal of Business and Management (IOSR-JBM) e-ISSN: 2278-487X, p-ISSN: 2319-7668. Volume 16, Issue 1. Ver. VI (Feb. 2014), PP 117-122 www.iosrjournals.org.

Haryanto R.A. 2013. Strategi Promosi, Kualitas Produk, Kualitas Layanan Terhadap Kepuasan Nasabah Pada Restoran MCDonals Manado. Jurnal Ekonomi Bisnis. Vol 1 No 3.

Herawati, Titin. (2013). Pengaruh Kebijakan Dividen, Kebijakan hutang, dan Profitabilitas, terhadap nilai perusahaa.Jurnal.Universitas Negeri Padang.

Ibrahim dan Windarti 2017.Pengaruh Kualitas Produk Dan Kualitas Layanan Terhadap
Kepuasan Nasabah Produk Donut Madu.Jurnal Manajemen Bisnis Vol 1 No 2.

Kotler, Philip, 2017, Manajemen Pemasaran, Jilid 2, Edisi 12, Jakarta, PT Indeks.

Machfoedz Mahmud, 2015, Pengantar Pemasaran Modern, edisi pertama, cetakan pertama, Penerbit : UPP AMP YKPN, Yogyakarta.

Mahmud 2013. Pengantar pemasaran modern.Yogyakarta : Upp Ykpn.

Mubbsher Munawar Khan, Mariam Fasih. 2014. Impact of Service Quality on Customer Satisfaction and Customer Loyalty: Evidence from Banking Sector. Pakistan Journal of Commerce and Social Sciences 2014, Vol. 8 (2), 331- 354.

Naryawan. 2014. Analisis pengaruh kualitas layanan terhadap kepuasan mahasiswa pengguna jasa perpustakaan referensi $\mathrm{FE}$ UNDIP. Skripsi Fakultas Ekonomi Universitas Diponogoro.

Parasuraman Et Al. 2013.The Nature And Determinants Of Customer Expextation Of Service. Journal of Academy of Marketing Science. 21. Pp. 1-12.

Sanjuq, D. 2014. Social and Cultural Perspectives in Nutrition. America: Prentice-Hall.

Sugiyono. 2017. Metode Penelitian Pendekatan Kuantitatitf, Kualitatif, dan R\&D, Bandung : Alfabeta.

Tjiptono, Fandy. 2016. Manajemen Jasa. Edisi pertama. Jogjakarta: Andi.

Utami Sulistyaningrum. 2014. Pengaruh kualitas pelayanan terhadap loyalitas

I Putu Ardinada

Ni Ketut Murdani

Ni Luh Ketut Ayu Sudha Sucandrawati 
Jurnal Satyagraha

Vol. 03, No. 02, Agustus 2020 - Januari 2021

ISSN : 2620-6358

http://ejournal.universitasmahendradatta.ac.id/index.php/satyagraha

pelanggan dengan kepuasan pelanggan.

Jurnal Manajemen. Vol 3 No 1.

Wahjono, Sentot Iman 2013, Manajemen

Pemasaran Bank.Yogyakarta : Graha

Ilmu.

Widjoyo Putro dan Sandy 2014 Pengaruh Kualitas Layanan Dan Kualitas Produk Terhadap Kepuasan Nasabah Dan Loyalitas Nasabah Restoran Happy Garden Surabaya. Skripsi.

Yamit, Zulian. 2001, Manajemen Kualitas Produk dan Jasa, Yogyakarta : Ekonosia.

Zeithami, et al 2016.Measuring The Quality Of Relationship in customer service : An Empirical Study. European. Journal Of Marketing..

Zeithmal, Valarie. A., Berry, Leonard. L., and Parasuraman, A. 2013. The Behavioral Consequences of Service Quality.Journal of Marketing.Vol . 60, pp . $31-46$.

Ni Ketut Murdani

Ni Luh Ketut Ayu Sudha Sucandrawati 